\title{
Evaluation of a Community Health Service Center-Based Intervention Program for Managing Chronic Heart Failure
}

\author{
Moli $\mathrm{Gu}^{2}$, Yanlan $\mathrm{Ma}^{2}$, Ti Zhou ${ }^{2}$, Yunfeng Xia ${ }^{1}$ \\ ${ }^{1}$ The Cadre Ward, No. 1 Hospital affiliated to General Hospital of the Chinese People's Liberation Army, Beijing, China \\ ${ }^{2}$ Department of Nursing, No. 1 Hospital affiliated to General Hospital of the Chinese People's Liberation Army, Beijing, China
}

Background: Although the role of primary care for the management of patients with chronic heart failure (CHF) has been highly recommended, structural involvement of primary care in heart failure (HF) management programs is extremely limited.

Aims: To examine the feasibility and applicability of two most recommended forms of care delivery mode, home visit and telephone support, for CHF management in the setting of community health service center (CHSC).

Study Design: Prospective study.

Methods: This study was conducted in two CHSCs in Beijing, China. Care delivery was led by trained general practitioners or community nurses via home visits in one CHSC and telephone support in the other. Data regarding the change in mortality and hospitalization rate during 12 months and self-care level at 6 months were prospectively collected and compared across the intervention groups.

Results: A total of 329 patients were included, with 142 in the home visit group and 187 in the telephone support group. Patients in both groups had frequent visits to CHSC $(8.1 \pm 5.9$ in the home visit and $7.7 \pm 4.1$ in the telephone support group, $\mathrm{p}=0.45$ ) during the follow-up period. Compared to the telephone support group, patients in the home visit group showed a reduction in all-cause mortality ( $14.1 \%$ versus $20.3 \%, p=0.14)$, one or more hospitalizations due to any cause $(33.8 \%$ versus $44.2 \%, \mathrm{p}=0.12$ ) and one or more hospitalizations due to cardiac cause $(17.6 \%$ versus $24.6 \%, \mathrm{p}=0.13)$ in the home visit group. The absolute differences were $6.2 \%$ (95\% CI: $1.9 \%, 14.3 \%$ ), $8.4 \%$ (95\% CI: $2.1 \%$, $18.9 \%)$ and $7.3 \%$ (95\% CI: $1.5 \%, 16.1 \%)$, respectively, although the results were not statistically significant. After 6 months of intervention, patients in both groups achieved marked improvement in self-care with reference to their own baseline values.

Conclusion: Although no statistical difference was observed between the two care delivery approaches regarding the clinical outcomes of interest, given the high participation rates, the acceptable rate of adverse events, frequent CHSC visits and patients' preferences in the current study, it was concluded that CHSC might be the optimal setting for delivering care to CHF patients in China. Keywords: Chronic heart failure, home visit, mortality rate, primary care, telephone support
Despite huge developments in treatment modalities and options, owing to the intensive nature and high treatment cost, the management of chronic heart failure (CHF) imposes a substantial financial burden to the healthcare system worldwide $(1,2)$. The prevalence of $\mathrm{CHF}$, according to the American heart association (3), has been estimated at $0.4 \%$ to $2 \%$ in the general population and from $2.3 \%$ to over $16 \%$ among those aged $>75$ years. In China, the prevalence of CHF has been reported as about $1 \%$ of the population aged $35-74$ years, with a total number of CHF patients being more than 8 million (4). With

Address for Correspondence: Dr. Yunfeng Xia, The Cadre Ward, No. 1 Hospital affiliated to General Hospital of the Chinese People's Liberation Army, Beijing, China Phone: +861066848711 e-mail: xiayunfeng 12@163.com

Received: 24.02.2015 Accepted: 03.07.2015 - DOI: 10.5152/balkanmedj.2015.150023

Available at www.balkanmedicaljournal.org

Gu M, Ma Y, Zhou T, Xia Y. Evaluation of a community health service center-based intervention program for managing chronic heart failure.

Balkan Med J 2016;33:45-51 
the increasing number of patients suffering from the chronic complications and the ongoing health service requirements $(5,6)$, a healthcare delivery model aimed at promoting selfcare has gained increasing attention around the world.

A number of randomized clinical trials, although varying widely in their specific content and focus, have consistently suggested that multidisciplinary management and follow-up of CHF patients could be effective in improving patient adherence to medication, reducing hospital readmissions and prolonging survival (7-11). However, the majority of these programs were primarily hospital-based (usually academic medical centers), with preferential care delivery centers being the outpatient clinics and sometimes at patients' home through outreach nursing staff having expertise in cardiac care. In the context of limited health funding and the associated scarcity of medical resources, it seemed difficult to provide consistent care to CHF patients solely by hospitals (12). Given the multiple advantages of primary care in the management of chronic diseases, some researchers supported strengthening of the role of primary care for the management CHF patients (13-15). However, the structural involvement of primary care (general practitioners and/or specialized community-based HF nurses) in HF management program is extremely limited in China.

In China, as a major model of primary care, community health service centers (CHSCs) play an increasingly important role in the prevention and control of non-communicable diseases $(16,17)$. Therefore, we conducted a CHSC-based, multidisciplinary management program for CHF patients led by general practitioners and community nurses. Same components of multidisciplinary care were applied via the two most recommended CHF management forms: home visit (direct contact with patients at their own home), and telephonic support (scheduled telephone contacts with patients) (18). The objectives of the present study were to examine: 1) the efficacy of CHF management program in the setting of CHSC, and 2) whether direct contact was superior to telephone support in terms of all-cause mortality, readmission rate and selfmanagement in the setting of CHSC.

\section{MATERIALS AND METHODS}

\section{Study setting and design}

This pilot study was conducted in the Haidian district in Beijing, China, between May, 2011 and June, 2014. Two community health centers, Dacishi and Bajiaozhuang, which were 5 kilometers apart and had a similar distribution of demographic parameters and standard of healthcare services, were selected as the study site. For logistic benefit, proximity to the research institute was also emphasized as an important factor for the site selection. Both centers had a health registration system for the local residents and facility for the treatment of CHF. While the patients residing in Dacishi were visited at home, patients from Bajiaozhuang were monitored over the telephone.

\section{Ethical aspects}

Written voluntary informed consent was collected from each participant after explaining every details pertaining to the study in a language that they understand properly. The study content and procedures were reviewed and approved by the Institutional Ethics Review Board (IERB) of the No. 1 Hospital Affiliated to the General Hospital of the Chinese People's Liberation Army.

\section{Recruitment}

Since the initiation of the program, in both centers, the records of the health registration system were explored and the list of the newly admitted patients was thoroughly searched by the research assistants to prepare an exhaustive list of CHF patients registered in these two centers. All patients were then screened for study eligibility according to the following criteria: 1) age $\geq 55$ years, 2) diagnosis of CHF confirmed by a cardiologist, 3) belonging to New York Heart Association (NYHA) functional class II to IV, and 4) admitted at least once with acute heart failure during the last year. Temporary residents, terminal cases of malignancy and patients who were going to undergo cardiac surgery were excluded from the study.

\section{Program implementation}

A multidisciplinary research team comprising of a dietitian, cardiologist, nursing staff with expertise in heart failure management and an epidemiologist was established in 2010. Specific experts of the team were responsible for the designing of the training modules, providing review and guidance to the program administrators, scheduling the follow-up plan and training of the community healthcare providers.

In both centers, 8 modules of a multi-component training plan were provided to the community physicians and nurses who were responsible for the management of CHF. Each of these modules was delivered at an interval of one week each and lasted for 2 days. Thus, over a span of 2 months, the following domains were covered: 1) overview of the pathophysiology of HF and details about the self-management concept, 2) assessment of the clinical stability of the patients and timely identification of the high risk, life-threatening events, 3) awareness development and motivation for behavior modi- 
fication, and 4) formulation as well as organization of the CHF management plan.

Patients in the home visit group were scheduled to receive their first home visit by trained community physicians or nurses 2-3 weeks after the completion of the recruitment, followed by three planned visits at 3-monthly intervals in the next year. Additional visits were to be scheduled for the patients with more serious conditions based on the assessment of their status. During each visit, community physicians or nurses conducted a comprehensive assessment of the clinical, physical and psychological conditions relevant to the ailment of each patient, a review of their past and current use of medications and acquired information regarding their social and familial support, daily diet and exercise habits. Based on the collected information, after a detailed discussion with the patient and seeking consultation from the program team, a comprehensive management plan was suggested.

Patients in the telephone support group were followed through bimonthly telephone conversations. The same operational principles for the assessment, suggestion and followup were applied for the management and monitoring of this group of patients.

In both centers, patients were encouraged to visit CHSCs regularly. Moreover, detailed information on the access and availability of the healthcare services was also provided, and the patients were instructed to contact the community physicians or nurses if there was any change in their physical condition.

\section{Outcome measurements and data collection}

Demographic and clinical data were collected at baseline by interviewing patients and/or reviewing the medical records. All surviving patients were followed up-for 1 year. Outcome variables including all-cause mortality, all-cause hospitalization and HF-specific hospitalization were measured based on the data collected during home visits or telephone calls.

Self-care behavior was measured by the Chinese version of the Self Care of Heart Failure Index Version 6 (SCHFIV6) (19). This is an ordinal, self-administered instrument that yields a performance rating score and has 3 subscales: self-care maintenance (10 items), self-care management (6 items) and self-care confidence (6 items). Its developer, Riegel et al. (20), recommended scoring the 3 subscales individually (scores range from 0-100) instead of determining a total summary score. Patients with higher scores have greater selfmanagement skills. The Chinese version of the SCHFI-V6 was first used in a study by Tung et al. (21), who reported an $\alpha$ coefficient for internal consistency of 0.635 for self-care maintenance, 0.716 for self-care management, and 0.860 for self-care confidence.

\section{Statistical analysis}

Statistical analysis was performed using SPSS for Windows (version 17.0, SPSS Inc.; Chicago, Illinois, USA). Differences between the 2 study cohorts were compared using chi-square analysis for categorical variables, Student-t test for normally distributed continuous data, and Mann-Whitney Z-test for non-normally distributed continuous data (including no. of diseases, the rate of hospitalizations etc.).

\section{RESULTS}

Overall, $573 \mathrm{CHF}$ patients were identified from the health registration system and new admission register of the selected community health centers. Among these patients, 381 (177 in the home-visit group and 204 in telephone-support group) met the criteria for inclusion. Of the 381 eligible CHF patients invited to participate in the study, $52(13.6 \%)$ refused. Thus,

TABLE 1. Baseline characteristics of the study cohorts, by groups

\begin{tabular}{|c|c|c|c|c|}
\hline Characteristic & $\begin{array}{c}\text { All } \\
(\mathrm{n}=329)\end{array}$ & $\begin{array}{l}\text { Home-visit } \\
(\mathrm{n}=142)\end{array}$ & $\begin{array}{c}\text { Telephone } \\
\text {-support } \\
(\mathrm{n}=187)\end{array}$ & $\mathrm{p}$ \\
\hline \multicolumn{5}{|l|}{ Demography } \\
\hline Mean Age in years \pm SD & $72.0 \pm 10.1$ & $72.3 \pm 9.6$ & $71.8 \pm 10.4$ & 0.66 \\
\hline Men $(\%)$ & $223(67.8)$ & $91(64.1)$ & $132(70.6)$ & 0.21 \\
\hline Han ethnicity (\%) & $315(95.7)$ & $135(94.8)$ & $180(96.4)$ & 0.60 \\
\hline Mean years of Education $\pm \mathrm{SD}$ & $11.5 \pm 5.5$ & $11.9 \pm 5.1$ & $11.2 \pm 5.7$ & 0.25 \\
\hline Living alone (\%) & $31(9.4)$ & $16(11.3)$ & $15(8.0)$ & 0.32 \\
\hline $\mathrm{BMI} \mathrm{kg} / \mathrm{m}^{2} \pm \mathrm{SD}$ & $27.3 \pm 6.3$ & $27.1 \pm 6.5$ & $27.5 \pm 6.2$ & 0.57 \\
\hline History of smoking (\%) & $154(46.8)$ & $61(43.0)$ & $93(49.7)$ & 0.22 \\
\hline \multicolumn{5}{|l|}{ Co morbidity } \\
\hline No. of diseases, Mean \pm SD & $2.1 \pm 1.1$ & $2.2 \pm 1.2$ & $2.0 \pm 1.1$ & 0.12 \\
\hline Hypertension (\%) & $193(58.7)$ & $81(57.0)$ & $112(59.9)$ & 0.60 \\
\hline Heart disease (\%) & $117(35.6)$ & $53(37.3)$ & $64(34.2)$ & 0.56 \\
\hline Diabetes (\%) & $72(21.9)$ & $28(19.7)$ & $44(23.5)$ & 0.41 \\
\hline Lung disease (\%) & $75(22.8)$ & $39(27.5)$ & $36(19.3)$ & 0.09 \\
\hline \multicolumn{5}{|l|}{ CHFc profile } \\
\hline Mean LVEF (\%) \pm SD & $38.0 \pm 10.7$ & $36.7 \pm 10.2$ & $38.9 \pm 11.4$ & 0.07 \\
\hline $\begin{array}{l}\text { NYHA functional } \\
\text { class II:III:IV }\end{array}$ & $170: 133: 26$ & $73: 59: 10$ & $97: 74: 16$ & 0.79 \\
\hline \multicolumn{5}{|l|}{ Pharmacotherapy } \\
\hline Beta blockers (\%) & $161(48.9)$ & $70(49.3)$ & $91(48.7)$ & 0.91 \\
\hline ACE inhibitors or ARBs (\%) & $199(60.6)$ & 89 (62.9) & $110(58.9)$ & 0.45 \\
\hline Digoxin (\%) & $81(24.6)$ & $29(20.6)$ & $52(27.7)$ & 0.12 \\
\hline $\begin{array}{l}\text { SD: standard deviation; BMI: body n } \\
\text { ventricular ejection fraction; NYHA: } \\
\text { converting enzyme; ARB: angiotensi }\end{array}$ & $\begin{array}{l}\text { lass index; } \mathrm{C} \\
\text { New York H } \\
\text { n receptor blc }\end{array}$ & $\begin{array}{l}\text { chronic hea } \\
\text { Association }\end{array}$ & lure; LVE & \\
\hline
\end{tabular}


TABLE 2. Comparison of mortality rate and readmission rate between two groups at 12 months

\begin{tabular}{|c|c|c|c|c|c|}
\hline Outcomes & All $(n=329)$ & Home visit $(\mathrm{n}=142)$ & Telephone support $(\mathrm{n}=187)$ & Absolute difference $(95 \% \mathrm{CI})$ & $\mathrm{p}$ \\
\hline All-cause mortality (\%) & $58(17.6)$ & $20(14.1)$ & $38(20.3)$ & $6.2(-1.9,14.3)$ & 0.14 \\
\hline $\begin{array}{l}\text { Patients with } \geq 1 \text { hospitalization } \\
\text { for all causes }(\%)\end{array}$ & $127(38.6)$ & $48(33.8)$ & $79(42.2)$ & $8.4(-2.1,18.9)$ & 0.12 \\
\hline $\begin{array}{l}\text { Patients with } \geq 1 \text { hospitalization } \\
\text { for } \mathrm{CHF}(\%)\end{array}$ & $71(21.6)$ & $25(17.6)$ & $46(24.6)$ & $7.3(-1.5,16.1)$ & 0.13 \\
\hline
\end{tabular}

TABLE 3. Self-Management at Baseline and 6 month in surviving patients, by groups

\begin{tabular}{lcccccc}
\hline & & Home visit $(\mathrm{n}=137)$ & & \multicolumn{3}{c}{ Telephone support $(\mathrm{n}=176)$} \\
\hline & baseline & 6 months & $\mathrm{p}$ & baseline & 6 months & $\mathrm{p}$ \\
Self-maintenance & $49.3 \pm 11.5$ & $58.1 \pm 15.7$ & $<0.01$ & $51.1 \pm 13.9$ & $57.2 \pm 14.4$ & $<0.01$ \\
Self-management & $41.7 \pm 9.7$ & $52.5 \pm 14.6$ & $<0.01$ & $42.2 \pm 10.3$ & $50.9 \pm 12.1$ & $<0.01$ \\
Self-confidence & $37.3 \pm 11.9$ & $43.1 \pm 14.9$ & $<0.01$ & $38.7 \pm 12.6$ & $43.9 \pm 13.8$ & $<0.01$ \\
\hline
\end{tabular}

altogether, 329 patients (142 in home-visit group and 187 in telephone-support group) were recruited for the study, interviewed, monitored and included in the follow-up. During the 12-month follow-up, 18 patients (7 in home visit group and 11 in telephone support arm) withdrew themselves from the study.

Demographic and clinical characteristics of the patients were shown in Table 1. Majority (67.8\%) of the patients were male with mean age 72.0 years (range: 55-86 years) having on average 2.1 co-morbidities. The number of patients in NYHA functional class II, III, IV was 170 (51.7\%), 133 (40.4\%) and 26 (7.9\%), respectively. Patients in the home-visit group were more likely to have lung diseases and lower Left Ventricular Ejection Fraction (LVEF \%) than their counterparts, although the difference was not statistically significant. Overall, both groups were fairly comparable regarding all baseline parameters.

During the 12-month follow-up, all patients in the home visit group received at least 1 to 2 visits, $83(85.6 \%)$ received 3 visits and 71 (73.2\%) received 4 or more visits, resulting in a median number of 3.9 visits (range: 1-9). In the telephone support group, patients received a median number of 7.7 telephone communications, ranging from 2 to 14 contacts. In addition, patients in both groups had frequent visits to CHSC (8.1 \pm 5.9 versus $7.7 \pm 4.1, p=0.45)$. Follow-up home visits identified 29 (20.4\%) individuals who required immediate or emergency medical management for unstable clinical conditions and were referred to tertiary hospitals. Similar events took place for $37(19.9 \%)$ patients in the telephone support group. In addition, $51(35.9 \%)$ patients who were visited at home and 64 (34.2\%) patients who were interviewed via telephone contacted the research team or CHSC health providers for counseling; these numbers were not statistically different $(\mathrm{p}=0.75)$.
As presented in Table 2, 58 (17.6\%) patients died during the study. While $20(14.1 \%)$ deaths occurred in the homevisit group, 38 (20.3\%) subjects died in the telephone-support group, showing no statistical difference between the groups $(\mathrm{p}=0.14)$. Although the proportion of patients who had to be admitted in hospital once or more were lower among homevisited patients compared to the telephone support group (33.8\% versus $44.2 \%)$, the results were not statistically different $(\mathrm{p}=0.12)$. Altogether there were 358 and 539 hospitalizations for any diagnosis in the home visit and telephone support groups, respectively. Rate (per month of follow-up/patient) of re-admissions was also not statistically different across these two groups $(0.21 \pm 0.25$ versus $0.26 \pm 0.30, \mathrm{p}=0.11)$. Similarly, the proportion of patients admitted for CHF in the home visit group was $17.6 \%$, while this proportion for the telephone support group was $24.6 \%(\mathrm{p}=0.13)$.

As shown in Table 3, two groups had similar scores at baseline in the subscale of self-maintenance $(\mathrm{p}=0.22)$, selfmanagement $(\mathrm{p}=0.66)$ and self-confidence $(\mathrm{p}=0.32)$. After 6 months, all the three aspects showed statistically significant changes in both groups when compared to their own baselines, demonstrating the effectiveness of both approaches in improving self-care for patients with CHF.

\section{DISCUSSION}

In this pilot study, we investigated the effectiveness of the two most commonly recommended post-discharge CHF management approaches, home visits and telephone support, in the setting of CHSC. Patients in the home visit group appeared to have better clinical outcomes in terms of mortality and hospitalization rate compared to those in the telephone support 
group. However, the differences did not reach statistical significance, implying that home visit might not bring substantial extra benefits over telephonic support to CHF patients in CHSC-based program for patients with CHF.

Similar findings were also reported by previous studies and varied explanations were suggested for the absence of a statistically significant difference in the clinical outcomes. In a prospective, multicenter, randomized controlled trial (The WHICH? Trial), patients allocated to home-based intervention received a comprehensive home visit 7-14 days after hospitalization by a HF nurse (22). The results showed a minimal difference between two groups with respect to all-cause death (mortality rate: $22 \%$ versus $28 \%$ ) or hospitalization. Stewart et al. (24) explained that the observed difference in effectiveness between the two groups was minimal, probably due to the high standard of initial post-discharge management in both groups. Similarly, in the COACH (Coordinating Study Evaluating Outcomes of Advising and Counseling in Heart Failure) study, Jaarsma et al. (23) reported that intensive support (home visits by specialized nurses) did not result in a substantial reduction of mortality (mortality: 38\% versus $42 \%$ ) and readmission rate compared to basic management and stated that patients in the control group were already so well managed, tha further improvement of the outcomes in the intervention group was very difficult. Some researchers also argued that the wide inclusion criteria could also have obscured the differences between the intervention and control group while a home visit might have been more effective for the frailest patients of increased age with multi-morbidity of maximum severity. These observations could possibly explain our results to some extent. However, given the study setting, it seemed insufficient to comprehensively understand the findings and it was, therefore, necessary to further identify factors that might have led to this outcome.

It is well known that all patient groups are not likely to benefit from the same intervention. Home visit were strongly recommended as an alternative form of care for frailest, most elderly patients, as the willingness or capabilities of these patients to regularly attend hospital or clinic-based programs might be reduced owing to their poor functional status, lack of available transport, multiple comorbidities and perceived inconvenience $(25,26)$. This might also partially be the reason behind the observation that some hospital- or clinic-based trials demonstrating higher effectiveness of the home-based care over hospital/clinics in reducing mortality and hospitalization rate, especially while applying narrow inclusion criteria (22). However, these difficulties might be partially lessened because of the close proximity, easy access and harmonious environment in the setting of CHSC. In the present study, patients in both groups had frequent visits to $\mathrm{CHSC}$ (on average
8.5 times in the telephone group and 7.7 in the home visit group), where they received standardized level of treatment and quality level of education and guidance regarding medication by trained health providers. This might, at least to some degree, have made the demand of home visits not so essential in CHSC-based programs as in hospital-based trials.

Another advantage of home-based care, as studies had revealed, was that it provided an opportunity for care providers to conduct comprehensive assessment of the patients at their own home (22). Thus, preparing a more specific and tailored CHF management plan was possible for patients with complex needs and therefore, leading to better clinical outcome. However, in the current CHSC-based study, care delivery for $\mathrm{CHF}$ patients was led by general practitioners or community nurses, unlike cardiac nurses, clinical pharmacists or cardiologists in hospital-based trials (27). These private practitioners and nurses were working and/or living in the same community as CHF patients for a long time. Moreover, the management of residents with serious chronic illness, as regulated by national law, was one of their main responsibilities and thus a routine work for them. They were probably, as previous studies indicated $(28,29)$, more familiar with patients' environment, psychosocial status and familial or social supports or obtained these data from the patients during their visits, not relying solely on home visit. This might also be a probable reason for the findings in the present study.

The reported 1-year mortality in patients receiving comprehensive CHF management with a multidisciplinary approach ranged between $11 \%$ and $30 \%$ and 1-year re-hospitalization rate was 30\%-70\% (9). These figures in both groups were either within the range or far lower than most of the previous reports $(10,12)$. Although the heterogeneity of design might have reduced the validity of direct comparison across studies, given the acceptable rate of adverse events during 1 year and the marked improvement of self-care after 6 month intervention, we believed that both approaches considerably improved the clinical outcomes of CHF patients in the primary care setting. The mechanism underlying the results, however, was difficult to elucidate. According to our anticipation, three components: involvement of the trained primary care providers, timely availability of the quality service in vicinity and working environment facilitating team work were crucial for the success of the current program. Patients could receive education and guidance from the same team members who were easily available locally at the time of requirement and the service quality was similar to that available from cardiologists in tertiary hospitals. Moreover, the multidisciplinary management team could bridge the gap between primary and tertiary care, thus minimizing the worries of the patients regarding the availability of treatment in the case of an emergency. The ap- 
preciation of these advantages could have helped them to gain confidence on health service providers, actively participate in CHSC based programs and thus enhance their self-management capability. This was also supported by the high participation, low withdrawal and frequent CHSC visits, as indicated by the results.

There were some limitations of the current study, warranting caution while interpreting the findings. The study was conducted in Beijing, a well-developed region in China, where health providers of CHSC had good educational background and were capable of providing standard services for patients according to the practice guidelines. This might arouse concern regarding its generalization to other regions. However, as a major model of primary care in urban China, CHSC was run, funded and subsidized by the government and management of CHF as a serious chronic illness was mandated by national law. Therefore, health providers could receive a similar level of training and their quality of services could be evaluated in the same reference frame.

Above all, in the present study, for CHF patents we did not observed a statistically significant difference between two different health care delivery modes: home visit and telephone support in the primary care setting regarding their effectiveness in terms of minimizing morality and the re-hospitalization rate. However, home visits were associated with more favorable outcomes than telephone support, implying its role in the rehabilitation of CHF patients. Given the observed decreased proportion of complications and enhanced self-care, as showed by the data, we believed that patients in both groups achieved better performance following the intervention. Moreover, CHSCs were likely to be the optimal setting, as indicated by the high participation, low withdrawal and frequent CHSC visits, for delivering care for patients with CHF in China. However, findings from the current study should be evaluated at multiple practice sites to examine their generalizability.

Ethics Committee Approval: Ethics committee approval was received for this study from the ethics committee of the Institutional Ethics Review Board (IERB) of the No. 1 Hospital Affiliated to the General Hospital of the Chinese People's Liberation Army.

Informed Consent: Written informed consent was obtained from patients who participated in this study.

Peer-review: Externally peer-reviewed.

Author contributions: Concept - M.G., Y.X.; Design - M.G.; Supervision - Y.X.; Resource - M.G.; Materials - Y.M.; Data Collection \&/or Processing - T.Z.; Analysis \&/or Interpretation - Y.X.; Literature Search - T.Z., Y.M.; Writing - M.G., Y.M., T.Z., Y.X.; Critical Reviews - M.G., Y.M., T.Z., Y.X.
Acknowledgements: The authors would like to express their sincere gratitude to the medical staff at Dacishi and Bajiaozhuang Community Health Service Center for their kind assistance in acquisition of data and field work.

Conflict of Interest: No conflict of interest was declared by the authors.

Financial Disclosure: The authors declared that this study has received no financial support.

\section{REFERENCES}

1. Chen J, Normand SL, Wang Y, Krumholz HM. National and regional trends in heart failure hospitalization and mortality rates for Medicare beneficiaries, 1998-2008. JAMA 2011;306:1669-78. [CrossRef]

2. Parissis J, Athanasakis K, Farmakis D, Boubouchairopoulou N, Mareti C, Bistola V, et al. Determinants of the direct cost of heart failure hospitalization in a public tertiary hospital. Int J Cardiol 2014;180C:46-9.

3. Go AS, Mozaffarian D, Roger VL, Benjamin EJ, Berry JD, Borden WB, et al; American Heart Association Statistics Committee and Stroke Statistics Subcommittee. Heart disease and stroke statistics--2013 update: a report from the American Heart Association. Circulation 2013;127:e6-e245. [CrossRef]

4. Dai G. Heart failure in China: review and prospect. Zhonghua Xin Xue Guan Bing Za Zhi 2015;43:104-7.

5. Maeder MT, Rickli H, Pfisterer ME, Muzzarelli S, Ammann $\mathrm{P}, \mathrm{Fehr} \mathrm{T}$, et al. Incidence, clinical predictors, and prognostic impact of worsening renal function in elderly patients with chronic heart failure on intensive medical therapy. Am Heart J 2012;163:407-14, 14 e1.

6. Curtis LH, Whellan DJ, Hammill BG, Hernandez AF, Anstrom $\mathrm{KJ}$, Shea AM, et al. Incidence and prevalence of heart failure in elderly persons, 1994-2003. Arch Intern Med 2008;168:418-24. [CrossRef]

7. Vuorinen AL, Leppanen J, Kaijanranta H, Kulju M, Helio T, van Gils M, et al. Use of home telemonitoring to support multidisciplinary care of heart failure patients in Finland: randomized controlled trial. J Med Internet Res 2014;16:e282. [CrossRef]

8. Smith CE, Piamjariyakul U, Wick JA, Spertus JA, Russell C, Dalton KM, et al. Multidisciplinary Group Clinic Appointments: The Self-Management and Care of Heart Failure (SMAC-HF) Trial. Circ Heart Fail 2014;7:888-94. [CrossRef]

9. McAlister FA, Stewart S, Ferrua S, McMurray JJ. Multidisciplinary strategies for the management of heart failure patients at high risk for admission: a systematic review of randomized trials. J Am Coll Cardiol 2004;44:810-9. [CrossRef]

10. Kasper EK, Gerstenblith G, Hefter G, Van Anden E, Brinker JA, Thiemann DR, et al. A randomized trial of the efficacy of multidisciplinary care in heart failure outpatients at high risk of hospital readmission. J Am Coll Cardiol 2002;39:471-80. [CrossRef] 
11. Azad NA, Molnar FJ, Byszewski AM. Multidisciplinary congestive heart failure clinic for older women: a randomized, controlled trial. J Am Geriatr Soc 2006;54:874-5. [CrossRef]

12. Wijeysundera HC, Trubiani G, Wang X, Mitsakakis N, Austin PC, Ko DT, et al. A population-based study to evaluate the effectiveness of multidisciplinary heart failure clinics and identify important service components. Circ Heart Fail 2013;6:68-75. [CrossRef]

13. Koh C. Chronic heart failure management in Australia--time for general practice centred models of care? Aust Fam Physician 2013;42:521.

14. Vilaseca J, Dedeu T, de Graaf P, Hobbs R, Muth C, Martensson $\mathrm{J}$, et al. Chronic heart failure: the role of primary care - position paper of the European Forum for Primary Care. Qual Prim Care 2008;16:351-62.

15. Ahmedov M, Green J, Azimov R, Avezova G, Inakov S, Mamatkulov B. Addressing the challenges of improving primary care quality in Uzbekistan: a qualitative study of chronic heart failure management. Health Policy Plan 2013;28:458-66. [CrossRef]

16. Chao J, Wang Y, Xu H, Yu Q, Jiang L, Tian L, et al. The effect of community-based health management on the health of the elderly: a randomized controlled trial from China. BMC Health Serv Res 2012;12:449. [CrossRef]

17. Zhao F, Zheng JZ, Chen BW, Xie XH. Analyses on the effect of community-based intervention on hypertension. Zhonghua Liu Xing Bing Xue Za Zhi 2003;24:897-900.

18. Stewart S, Carrington MJ, Marwick T, Davidson PM, Macdonald $\mathrm{P}$, Horowitz J, et al. The WHICH? trial: rationale and design of a pragmatic randomized, multicentre comparison of homevs. clinic-based management of chronic heart failure patients. Eur J Heart Fail 2011;13:909-16. [CrossRef]

19. Riegel B, Lee CS, Dickson VV, Carlson B. An update on the self-care of heart failure index. J Cardiovasc Nurs 2009;24:48597. [CrossRef]

20. Riegel B, Carlson B, Moser DK, Sebern M, Hicks FD, Roland V. Psychometric testing of the self-care of heart failure index. $J$ Card Fail 2004;10:350-60. [CrossRef]
21. Tung HH, Chen SC, Yin WH, Cheng CH, Wang TJ, Wu SF. Self care behavior in patients with heart failure in Taiwan. Eur J Cardiovasc Nurs 2012;11:175-82.

22. Stewart S, Carrington MJ, Marwick TH, Davidson PM, Macdonald P, Horowitz JD, et al. Impact of home versus clinic-based management of chronic heart failure: the WHICH? (Which Heart Failure Intervention Is Most Cost-Effective \& Consumer Friendly in Reducing Hospital Care) multicenter, randomized trial. J Am Coll Cardiol 2012;60:1239-48. [CrossRef]

23. Jaarsma T, van der Wal MH, Lesman-Leegte I, Luttik ML, Hogenhuis J, Veeger NJ, et al. Effect of moderate or intensive disease management program on outcome in patients with heart failure: Coordinating Study Evaluating Outcomes of Advising and Counseling in Heart Failure (COACH). Arch Intern Med 2008;168:316-24. [CrossRef]

24. Stewart S, Horowitz JD. Home-based intervention in congestive heart failure: long-term implications on readmission and survival. Circulation 2002;105:2861-6. [CrossRef]

25. Ekman I, Andersson B, Ehnfors M, Matejka G, Persson B, Fagerberg B. Feasibility of a nurse-monitored, outpatient-care programme for elderly patients with moderate-to-severe, chronic heart failure. Eur Heart J 1998; 19:1254-60. [CrossRef]

26. Whitty JA, Stewart S, Carrington MJ, Calderone A, Marwick T, Horowitz JD, et al. Patient preferences and willingness-topay for a home or clinic based program of chronic heart failure management: findings from the Which? trial. PLoS One 2013;8:e58347. [CrossRef]

27. Ritzema J, Troughton R, Melton I, Crozier I, Doughty R, Krum $\mathrm{H}$, et al. Physician-directed patient self-management of left atrial pressure in advanced chronic heart failure. Circulation 2010;121:1086-95. [CrossRef]

28. Chen XJ, Gao XL, You GY, Jiang J, Sun XL, Li X, et al. Higher blood pressure control rate in a real life management program provided by the community health service center in China. BMC Public Health 2014;14:801. [CrossRef]

29. Liu LJ, Li Y, Sha K, Wang Y, He X. Patient assessment of chronic illness care, glycemic control and the utilization of community health care among the patients with type 2 diabetes in Shanghai, China. PLoS One 2013;8:e73010.[CrossRef] 